\section{Commentary: Reoperative apical myectomy, a long run for a short slide, or a clear benefit yet to be determined}

\author{
Afshin Ehsan, MD, ${ }^{a}$ and Martin S. Maron, MD $^{\mathrm{b}}$
}

For more than 60 years, surgical septal myectomy has proven to be the most effective and definitive strategy for reversing progressive heart failure symptoms due to left ventricular (LV) outflow tract obstruction in patients with drug-refractory advanced heart failure. In experienced hypertrophic cardiomyopathy (HCM) centers, surgical myectomy has a low operative mortality $(<1 \%)$ and is responsible for relief of symptoms in $90 \%$ to $95 \%$ of patients, while also providing a survival benefit. In a small proportion of cases ( $4 \%$ ), myectomy fails to achieve symptom relief, even after the outflow gradient has been abolished. In such nonresponders, other mechanisms emerge as responsible for symptoms, including comorbidities, and systolic or diastolic dysfunction.

In their report, Sun and colleagues ${ }^{1}$ examine the outcomes of 6 patients with advanced heart failure symptoms after previous transaortic septal myectomy who underwent reoperative transapical myectomy to enlarge the LV cavity with the primary intention of increasing stroke volume and lowering diastolic filling pressures. Over an average followup of 0.6 years, the authors report an increase in the end systolic and end diastolic chamber size resulting in an improvement in physical capacity and patient-perceived functional status in 5 of the patients.

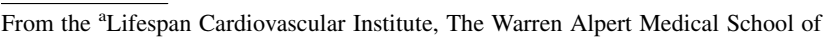
Brown University, Providence, RI; and ${ }^{\mathrm{b}}$ Hypertrophic Cardiomyopathy Center and Research Institute, Tufts Medical Center, Boston, Mass.

Disclosures: The authors reported no conflicts of interest.

The Journal policy requires editors and reviewers to disclose conflicts of interest and to decline handling or reviewing manuscripts for which they may have a conflict of interest. The editors and reviewers of this article have no conflicts of interest.

Received for publication Nov 8, 2021; revisions received Nov 8, 2021; accepted for publication Nov 12, 2021; available ahead of print Nov 17, 2021.

Address for reprints: Afshin Ehsan, MD, Lifespan Cardiovascular Institute, The Warren Alpert Medical School of Brown University, 2 Dudley St, MOC Suite 360, Providence, RI 02905 (E-mail: aehsan@lifespan.org).

JTCVS Techniques 2022;11:27-8

2666-2507

Copyright (C) 2021 The Author(s). Published by Elsevier Inc. on behalf of The American Association for Thoracic Surgery. This is an open access article under the CC BY-NC-ND license (http://creativecommons.org/licenses/by-nc-nd/4.0/).

https://doi.org/10.1016/j.xjtc.2021.11.010
}

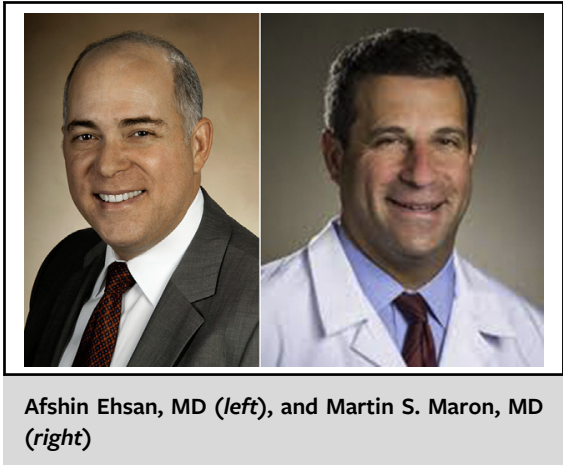

CENTRAL MESSAGE

Although reoperative apical myectomy results in improved symptoms, it brings to question whether these patients stand to benefit enough to justify undergoing a complex reoperation.

The authors first reported the approach described in the report for patients with nonobstructive apical HCM but now describe its potential application in HCM patients who had previously undergone successful septal myectomy. ${ }^{2}$ The rationale to consider apical myectomy in these patients was on the basis of the authors previous report which showed improvement in patient symptoms attributed to augmentation of stroke volume and therefore cardiac output by increasing LV cavity size. The authors also suggest that the benefit of apical myectomy can be attributed to improved LV compliance. However, whether the procedure also results in an improvement in diastolic function remains uncertain. Measurement of diastolic function before and after surgery using either traditional echocardiographic approaches or cardiac magnetic resonance imaging, would give further insight into the potential physiologic benefits of the procedure.

As it relates to the efficacy of apical myectomy in this situation, 3 of the 5 patients experienced only "some" improvement in symptoms. Assessment of clinical status was limited to a subjective survey questionnaire with all of the expected limitations of such methodology. It would be important to obtain follow-up imaging to determine if the morphologic changes noted immediately after surgery remained the same or changed, including whether systolic dysfunction could have developed and therefore be responsible for relatively suboptimal improvement in heart failure 
symptoms. With that said, it brings to question whether these patients stand to benefit enough to justify undergoing a complex reoperation. Longer follow-up might serve to clarify this concern.

This is clearly a very unique and highly select patient subset, as evidenced by the small number of patients from a large-volume HCM center. With such a small cohort, one is left to consider how translatable these outcomes are even at other high-volume HCM centers with expertise in subaortic myectomy but without an experience in performing apical myectomies. We commend the authors on the valuable contribution their results will make toward this unique surgical treatment option for this complex patient population. They have enlightened us on the potential to treat this challenging group of patients while also reminding us of the importance of specialized centers of excellence to treat patients with HCM.

\section{References}

1. Sun D, Schaff HV, Nishimura RA, Geske JB, Dearani JA, Ommen SR. Surgical management of diastolic heart failure after septal myectomy for obstructive hypertrophic cardiomyopathy. J Thorac Cardiovasc Surg Tech. 2022;11:21-6.

2. Schaff HV, Brown ML, Dearani JA, Abel MD, Ommen SR, Sorajja P, et al. Apical myectomy: a new surgical technique for management of severely symptomatic patients with apical hypertrophic cardiomyopathy. J Thorac Cardiovasc Surg. 2010; 139:634-40. 